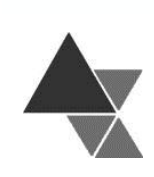

\title{
Agroecologia nas políticas públicas e promoção da segurança alimentar e nutricional
}

\author{
Flaviane de Carvalho Canavesi ${ }^{1}$, Iracema Ferreira de Moura $^{2}$ e Cláudia de Souza ${ }^{3}$
}

O artigo tem como objetivo apontar avanços, limites e desafios em relação à institucionalização da agroecologia no Brasil na perspectiva da garantia da segurança alimentar e nutricional. Para isso, apresentam-se e analisam-se o marco jurídico institucional e as principais políticas públicas que estabelecem as bases para tratar ambos os temas na agenda de governo. O período de análise compreende desde a Política Nacional de Assistência Técnica, em 2003, atéo decreto da Política Nacional de Agroecologia e Produção Orgânica, em 2012. No Brasil, vigora a Lei Orgânica de Segurança Alimentar e Nutricional no 11.346/2006, cujas ações de governo em torno do tema culminam com o Direito Humano à Alimentação Adequada. Desde a década de 1980, o movimento agroecológico brasileiro reivindica políticas públicas efetivas para o desenvolvimento rural, na perspectiva da construção de um novo modelo de agricultura em bases sustentáveis, consolidado, sobretudo, pela agricultura familiar. No entanto, somente em 2012, instituiu-se a Política Nacional de Agroecologia e Produção Orgânica com grande interface com as ações de segurança alimentar e nutricional num contexto da hegemonia do agronegócio voltado à exportação de commodities como fator limitante tanto da transição agroecológica quanto da garantia da segurança alimentar e nutricional.

Palavras-chave: Políticas Públicas; Agroecologia; Segurança Alimentar e Nutricional.

\section{Agroecology in the Public Policies and Promotion of Food Security and Nutrition}

The article aims to point out advances, limits and challenges for agroecology of institutionalization in Brazil with a view to ensuring food security and nutrition. For this, analyzes the legal and institutional framework and the main public policies that establish the foundation to address both issues in the government agenda. The analysis period explains since its National Politics of Rural Extension, in the year of 2003, there until the National Politcs of Agroecology and Organic Production, in the year 2012. In Brazil, we have the Organic Law on Food Security and Nutrition n. 11.346/2006 whose government actions around the theme culminate with the Human Right to Adequate Food. Since the 1980s, the Brazilian agro-ecological movement calls for effective public policies for rural development from the perspective of building a new model of agriculture on a sustainable basis, which was consolidated, especially in family agriculture and agrarian reform. However, only in 2012 is established the National Policy for Agroecology and Organic Production with great interface those Food Security and Nutrition actions in agribusiness hegemony of context facing the export of commodities as a limiting factor for both agro-ecological

\footnotetext{
1 Professora Doutora. Faculdade de Agronomia e Medicina Veterinária da Universidade de Brasília (FAV/UnB). Endereço para correspondência: Faculdade de Agronomia e Medicina Veterinária. Ala Central do Instituto Central de Ciências (ICC) Campus Darcy Ribeiro. CEP 70910-900. Brasília, Distrito Federal. E-mail: flavianecanavesi@unb.br

2 Doutora em Ciência, Tecnologia e Inovação na Agricultura pela Universidade Federal Rural do Rio de Janeiro (UFRRJ). Analista Técnica de Políticas Sociais. E-mail: iracemamoura2000@yahoo.com.br

${ }^{3}$ Doutoranda no Programa de Pós-Graduação em Desenvolvimento Sustentável do Centro de Desenvolvimento Sustentável (PPG-CDS), Universidade de Brasília (UnB). E-mail: sclaudias@gmail.com
} 
transition as the guarantee of food security and nutrition.

Keywords: Public Policies; Agroecology; Food Security and Nutrition.

\section{INTRODUÇÃO}

O presente artigo trata da inserção da agroecologia nas políticas públicas de desenvolvimento rural no Brasil. Analisamos avanços, limites e desafios das ações em um contexto de hegemonia do agronegócio, caracterizado nas suas dimensões econômica, social, política e ambiental. Argumentamos que as relações assimétricas do agronegócio com o desenvolvimento rural baseado na agroecologia e na agricultura familiar podem afetar a garantia da segurança alimentar e nutricional (SAN).

O Brasil inova na agricultura por meio do aperfeiçoamento de técnicas e conhecimentos, desde a década de 1940, embasados na denominada "Revolução Verde". Incentivado e impulsionado pelas políticas de Estado, esse tem sido o modelo hegemônico operado pelo desenvolvimento do capitalismo no campo. Ele introduziu o padrão de subjugação da agricultura ao capital industrial, tornando-a, em grande parte, dependente do uso de insumos externos.

O modelo da Revolução Verde foi apresentado como aquele que modernizaria o campo brasileiro. Ele se basearia no aumento da produção e da produtividade agrícola, mantendo intacta a estrutura agrária concentrada até então vigente no Brasil: é o que Wanderley [1] define como "modernização conservadora". Se por um lado, esse modelo foi o responsável pelo relativo êxito econômico do agronegócio brasileiro; por outro, impactos puderam ser evidenciados em relação aos aspectos ambientais (perda da biodiversidade, erosão e contaminação dos solos e da água), sociais e culturais (êxodo rural, concentração de terras e riquezas) e, sobretudo, à permanência de fatores que levam, ainda hoje, à insegurança alimentar. Considerado como a única forma de superação da fome pelo incremento na produção de alimentos, tal aspecto, de fato, não ocorreu. Segundo dados da FAO [2], o número de pessoas subnutridas no mundo foi elevado a mais de 1 bilhão em 2009.
Ao mesmo tempo em que o processo da modernização da agricultura se intensifica, movimentos sociais passaram a se organizar e questionar impactos negativos e suas causas, dentre eles, a permanência da estrutura agrária concentrada. É assim que movimentos camponeses de luta por terra e território passaram a contestar e a atuar, principalmente por meio de ocupações de terras, na segunda metade da década de 1980. Surgiram também neste período experiências alternativas de organização e produção que contestavam o padrão tecnológico que se solidificava por meio do aparato do Estado.

É no contexto de disputas que se formula um conjunto de instrumentos, reconhecendo perspectivas distintas para a agricultura e que se concretiza no Brasil, dentre outros, pelo Decreto no 7.794, de 20 de agosto de 2012. Entende-se, portanto, que lutas e resistências empreendidas pelo movimento agroecológico brasileiro distanciam-se dos padrões do agronegócio conforme caracterizamos nesta introdução.

Para estruturar o artigo apresentaremos uma maior caracterização do histórico do movimento agroecológico e de seus principais atores. Na sequência do artigo, trazemos as principais iniciativas de políticas públicas com o objetivo de focalizar o processo que antecede a construção da Política Nacional de Agroecologia e Produção Orgânica (PNAPO). O recorte do artigo se dá a partir do período que compreende a elaboração da Política Nacional de Assistência Técnica e Extensão Rural, em 2003, considerada como uma das primeiras a incorporar o enfoque agroecológico até a PNAPO, instituída em 2012.

Os procedimentos metodológicos para a elaboração do artigo consistiram em pesquisa qualitativa, levantamento, análise e sistematização de referencial teórico e de dados secundários sobre políticas públicas, agroecologia e segurança alimentar, além da interlocução com atores que protagonizaram e participaram sobretudo na PNAPO. Os momentos de interlocução aconteceram principalmente a partir do 
acompanhamento e participação em eventos nacionais e regionais de formulação da PNAPO.

\section{O Desenvolvimento Rural baseado na Agricultura Familiar versus o Agronegócio}

Analisando o contexto da modernização na agricultura, Assis [3] (p. 11) afirma que:

\begin{abstract}
a partir do final da década de 1980, este processo se mostrou extremamente danoso, particularmente para os países subdesenvolvidos. A "industrialização" da agricultura determinou um aumento crescente de problemas de degradação ambiental aliado a uma maior concentração da posse da terra e exclusão social, opostamente ao desejado, em razão da má distribuição da abundância gerada e o número de famintos no mundo.
\end{abstract}

Desta forma, iniciou-se na década de 1980 uma disputa por projetos e concepções de alternativas do desenvolvimento, baseando-se na urgência de uma reforma agrária, no combate à fome e à miséria e na busca de uma "agricultura alternativa", como se convencionava chamar. Contudo, intensifica-se o modelo de desenvolvimento rural que vinha sofrendo críticas, caracterizado por Delgado [4] como projeto neoliberal do agronegócio.

$\mathrm{Na}$ década de 1980, o termo agribusiness, definido em 1957 por Davis e Goldbergs, foi traduzido no Brasil para agronegócio envolvendo não só os produtos agropecuários, mas também os florestais. Muller ${ }^{[5]}$ procurou demonstrar a tendência crescente de integração da estrutura produtiva com o setor de serviços e os fornecedores de insumos, conformando complexos. Na mesma direção, Silva ${ }^{[6]}$ o definiu como 'Complexos Agroindustriais (CAIs)', ou seja, “[...] estruturas complexas, heterogêneas e multideterminadas [...] com suas dinâmicas específicas e interligadas aos setores industriais fornecedores de insumos e processadores de produtos agropecuários".

Mendonça [7] destaca que a noção de agribusiness organizou e instrumentalizou um poderoso complexo de operações de cunho muito mais comercial e financeiro e cuja importância não pode ser aquilatada, apenas, por seu desempenho econômico, mas, sobretudo, por sua influência política.
O termo agronegócio na acepção brasileira é "uma associação do grande capital agroindustrial com a grande propriedade fundiária. Essa associação realiza uma estratégia econômica de capital financeiro, perseguindo o lucro e a renda da terra sob o patrocínio de políticas de Estado" [8] (p. 64).

Segundo Alentejano [9], o agronegócio deve ser entendido pela sua dimensão econômica (conjunto de empresas que concentra grande poder financeiro e controla o desenvolvimento de tecnologias para a agricultura, pecuária e indústria, induzindo a população ao consumo de alimentos industrializados), pelas relações sociais (concentra terra e riqueza, expropria agricultores, causa desemprego, superexploração do trabalho), pela dimensão política (bloqueio a mudanças legislativas e decretos presidenciais) e ambiental (poluição, desmatamento, uso indevido da água).

Assim, o agronegócio se amplia simultaneamente aos movimentos contrahegemônicos, a partir da construção de alternativas e superação que vão tensionando o Estado no sentido de criar mecanismos públicos que combatam as mazelas do desenvolvimento desigual e concentrador de terras e de riquezas.

Ainda que exista um amplo debate sobre o papel da agricultura familiar no desenvolvimento rural, Schneider [10] utiliza três modos de decifrá-la: o primeiro relacionado à forma de uso do trabalho, entendendo que os membros da família utilizam-na, mas podem contratar trabalhadores temporários; o segundo, considerando os obstáculos oferecidos pela natureza, porque apesar de todos os esforços científicos e tecnológicos, ainda não se conseguiu eliminar a 'barreira natural' e; o terceiro tendo sido extraído da teoria social, a partir da compreensão das formas de articulação da agricultura familiar com o ambiente social e econômico em que estiver inserida. Para o autor, o espaço rural ganhou atribuições tornando-se um lugar de múltiplas atividades produtivas e ocupacionais, dentre elas, o consumo de bens materiais e simbólicos e os serviços trazendo a necessidade de se fazer uma analogia entre o processo de reestruturação da agricultura e o papel desempenhado pela pluriatividade presente na realidade das atividades desenvolvidas pela agricultura familiar que contribuem para a sua reprodução social. 
Até o início dos anos 2000 era clara a necessidade de estruturação das políticas públicas para o segmento da agricultura familiar. O potencial econômico do setor não era devidamente reconhecido, apesar do seu papel relevante para o crescimento sustentável do País. A modernização tecnológica não significou melhoria nas condições de trabalho e de renda das populações rurais brasileiras.

O modelo econômico e agrícola implantado resultou em um quadro de: preços agrícolas em queda e oscilação constante; a concentração da produção em poucos produtos, principalmente commodities para exportação; o endividamento crescente de praticamente todos os segmentos produtivos do setor agropecuário; a depreciação patrimonial e a crise de setores importantes da agricultura; a internacionalização dos setores a jusante e a montante da agricultura brasileira, aumentando a vulnerabilidade externa do País; o agravamento da concentração fundiária e; $\mathrm{O}$ empobrecimento dos agricultores, especialmente no setor da agricultura familiar.

Veremos que o histórico do movimento agroecológico e os principais atores que o compõem estão no cerne da ação/pressão política consciente e dirigida a obter certos objetivos no interior do quadro descrito antes. Considera-se, segundo Gramsci [11], que o consenso ou o consentimento, é obtido através dos aparelhos privados de hegemonia, bem como através da ação do Estado que busca promover e generalizar a visão da fração de classe hegemônica. São visões de mundo organizadas, que disputam entre si, a todo o tempo, a imposição de uma cultura contra-hegemônica [12]. Nesta disputa participam as políticas públicas para a agroecologia que se estruturam a partir do campo da agricultura familiar, categoria delimitada pela Lei no 11.326/2006 (conhecida como Lei da Agricultura Familiar), alterada pela Lei no 12.058/2009 e pela Lei oㅡ 12.512/2011.

A agroecologia é apresentada em tópico posterior na sua relação com a construção da Política Nacional de Segurança Alimentar e Nutricional, no Brasil. Este entendimento se baseia na discussão do próprio conceito de agroecologia que hoje considera os "processos endossomáticos dos cidadãos" [13]. Nesta

${ }_{4}^{4}$ Organizaram-se nessa década: o Movimento dos Trabalhadores Rurais Sem Terra (MST,) o Movimento dos Atingidos por Barragens (MAB), o Conselho Nacional dos Seringueiros (CNS) e o Movimento de Mulheres Trabalhadoras Rurais (MMTR), além do advento do Novo Sindicalismo, restabelecendo os Sindicatos de Trabalhadores Rurais (STR) e a Confederação Nacional dos Trabalhadores na Agricultura (CONTAG). Dentre, as organizações não governamentais com acepção aparecem elementos para além dos componentes técnico-agronômicos, dos agroecossistemas, sociais e a relação entre ambos [14]. Segundo Molina [13], significa a garantia dos processos de distribuição e segurança alimentar que envolve, produção, elaboração e transformação, transporte, distribuição, conservação e preparação dos alimentos. Tais processos obrigam a adotar uma visão do fenômeno agrícola mais ampla do que a meramente produtiva e neste sentido, considerar o "metabolismo agrário" proposto pelo autor. Resulta na promoção de uma transição socioecológica que afeta formas e distribuição de alimentos.

Nesta perspectiva, define-se a agroecologia como o manejo ecológico dos recursos naturais por meio de ação social coletiva [15], capaz de promover na contra-hegemonia a ampliação do acesso e melhoria da qualidade dos alimentos e assegurar a segurança alimentar e nutricional.

\section{O Movimento Agroecológico}

A década de 1980, pós-abertura política no Brasil, foi marcada pelo advento de novas perspectivas para o desenvolvimento, pautada pelos movimentos sociais e organizações não governamentais que começaram a se (re)organizar4.

No contexto de contra-hegemonia ao modelo de desenvolvimento em curso, a atuação das Comunidades Eclesiais de Base (CEBs) passou a ser um exemplo de vínculo orgânico com as classes subalternas. Os processos educativos foram associados ao processo produtivo e às lutas dos trabalhadores, compondo uma visão e modo de "transformação do mundo".

Houve um novo significado à participação consensuada que se vinha conotando como suporte à modernização da agricultura para uma participação crítica e contestatória das condições da classe trabalhadora no campo ${ }^{[16]}$. importante papel de assessoria e formação aos trabalhadores rurais, devem ser citadas, a Associação Brasileira de Reforma Agrária (ABRA), a Federação dos Órgãos Assistenciais e Educacionais de Base (Fase), o Centro Ecumênico de Documentação e Informação (CEDI) e o Instituto Brasileiro de Análises Sociais e Econômicas (IBASE). Estes movimentos hoje, em sua maioria, compõe a Articulação Nacional de Agroecologia. 
As CEBs estimularam a organização e a resistência política à ditadura militar, mas também uma construção de alternativas aos impactos sofridos pelo modelo de desenvolvimento em curso. Estabelecia-se uma relação de enfrentamento dos problemas do concreto da vida cotidiana com a dimensão macro do modelo de desenvolvimento excludente. O movimento agroecológico, em certa medida, foi herdeiro desse processo.

Como afirmam Petersen e Dias [17], o movimento foi crucial para os debates em torno da denominada "agricultura alternativa", cuja noção "alternativa", à época, vinha da necessidade de diferenciarem-se modelos técnicos dominantes em franca difusão, daqueles mais comprometidos com questões socioambientais.

Como afirmam os autores [17] (p. 11),

a partir do início da década de 1980, a construção do movimento agroecológico se processou essencialmente por meio da interação das comunidades rurais e organizações de base estimuladas pelas CEBs, com instituições de assessoria comprometidas com a viabilidade social e econômica da agricultura familiar (camponesa) e portadoras de uma proposta de agricultura alternativa à Revolução Verde.

A assessoria aos agricultores na busca de alternativas surgiu principalmente a partir da Rede de Tecnologias Alternativas (Rede PTA) e ampliou com os Encontros Brasileiros de Agricultura Alternativa (EBAA).

Na década de 1990, após este movimento pró agricultura alternativa, as bases para a construção do movimento agroecológico no Brasil começaram a se solidificar. As estratégias foram constituídas a partir da promoção dos agricultores como agentes de transformação social e da revalorização dos seus conhecimentos nos processos de desenvolvimento e na conformação de estilos de agriculturas mais sustentáveis. Nesse ínterim, conforme destaca Gliessman ${ }^{[18]}$, a agroecologia teve influência importante dos sistemas tradicionais de cultivo, sobretudo indígenas e camponeses, de países em desenvolvimento, que começaram a ser reconhecidos por muitos pesquisadores como exemplos importantes de manejo de agroecossistemas, ecologicamente fundamentados.
No Brasil, o protagonismo da agricultura familiar e camponesa desenvolveu alternativas, uma vez que tal segmento, possuía estrutura que favorecia a consecução de objetivos ecológicos mais amplos por características como a maior disponibilidade de mão de obra, conhecimento de manejos complexos, diversidade, versatilidade das estratégias de uso múltiplo ou adaptação tecnológica [19].

Para Sevilla Guzmán [15], a agroecologia é definida como o manejo ecológico dos recursos naturais por meio de formas de ação social coletiva. Sua estratégia de natureza sistêmica considera a área dos agricultores, a organização comunitária e a relação das sociedades rurais articuladas em âmbito local. Segundo o autor, é dessa forma que se encontram os sistemas de conhecimento (local, camponês e/ou indígena) portadores do potencial endógeno que permite potencializar a biodiversidade ecológica e sociocultural.

Compreende-se também a agroecologia como uma ciência que possibilita redesenhar sistemas de produção sem perder de vista a busca por autonomia dos agricultores frente aos complexos agroalimentares [20], além de envolver os processos de segurança alimentar que envolve a produção, elaboração e transformação, transporte, distribuição, conservação e preparação dos alimentos. Segundo Molina [13], tal processo obriga a adotar uma visão do fenômeno agrícola mais ampla do que a meramente produtivista.

A agroecologia, entendida no contexto de enfrentamento de projetos diferentes de desenvolvimento, requer que os movimentos mantenham-se articulados em torno de uma agenda propositiva, principalmente quando se trata de tensionar o Estado na efetivação de políticas públicas.

A partir de 2002, como demonstração da capacidade organizativa de agricultores familiares e das entidades de assessoria à construção da agroecologia foram realizados Encontros Nacionais de Agroecologia (ENA). Eles reuniram diferentes sujeitos do campo com uma atuação que coaduna por um lado com a pauta política contrária ao avanço do agronegócio sobre os territórios e, por outro, com a construção de uma agricultura camponesa que disputa políticas públicas para a sua efetivação. É no ambiente do primeiro ENA, 
realizado no Rio de Janeiro, em 2002, que a Articulação Nacional de Agroecologia (ANA) ${ }^{5}$ foi formada.

O movimento agroecológico, hoje articulado em rede através da ANA, é composto de múltiplas e distintas organizações como as não governamentais, movimentos sociais de luta pela terra, sindicais, de trabalhadores rurais, organizações de representação de agricultores familiares, movimentos de mulheres, instituições no campo tecnocientífico, indígenas, quilombolas e juventude, para citar alguns. Assim, os sujeitos que reivindicam políticas públicas para a agroecologia e produção orgânica organizam-se desde a década de 1980, com forte cunho democrático e de pressão para a abertura de agendas para possibilitar o aumento de escala das experiências agroecológicas, base local de atuação prática destes movimentos.

Ainda que vários sujeitos do campo se organizem em torno de uma pauta - a agroecologia, através da então organizada ANA, é importante considerar os demais meios de diálogo, pressão e representação que cada um dos movimentos em particular tem com relação ao Estado, em outras pautas específicas com ou sem interface com a agroecologia. Nestas diversas interações expressam-se cada uma das identidades dos distintos movimentos que compõem a ANA.

Assim, o movimento agroecológico estabeleceu as condições para disputar uma agenda de políticas públicas.

Ao longo de várias iniciativas de formulação de políticas públicas onde o tema da agroecologia reverberou, a ANA, no conjunto de seus movimentos de representação, foi a principal interlocutora com o Estado. Essa atuação refletiu sobre a incisiva participação na elaboração do decreto da Política Nacional de Agroecologia e Produção Orgânica (PNAPO).
Ao longo de 2011, seminários regionais e um seminário nacional foram promovidos com o incentivo, principalmente, do Ministério do Meio Ambiente, proporcionando ao movimento agroecológico as condições para estabelecer as suas reivindicações para o Estado brasileiro. Concluímos que em parte elas foram atendidas pela Política decretada, a PNAPO, e pelo subsequente I Plano Nacional de Agroecologia e Produção Orgânica (2013-2015) [21].

No contexto de emergência de uma agricultura dita moderna expressa no agronegócio brasileiro é importante localizarmos que, resultante de forças históricas contraditórias, o movimento agroecológico vai participar da discussão de ações pontuais do Estado. Isso se dá em interface com a agroecologia ao longo dos anos 1990 e 2000 e, sobretudo da formulação da PNAPO, instituída pelo Decreto no 7.794 , de 20 de agosto de 2012.

Em tópico posterior delimitaremos as principais políticas públicas e a relação delas para a promoção da segurança alimentar e nutricional.

\section{Agroecologia e Segurança Alimentar e Nutricional}

A institucionalização da agroecologia nas políticas públicas foi ancorada na promoção de um novo modelo de desenvolvimento sustentável visando fortalecer a agricultura familiar, com desejáveis impactos positivos sobre as dimensões sociais, ambientais e sobre a dinamização de economias e desenvolvimentos locais.

Concomitantemente, no bojo de pressões sociais, desencadeava-se no Estado brasileiro a construção de um marco legal de segurança alimentar e nutricional culminando com o reconhecimento do Direito Humano à Alimentação Adequada (DHAA), assegurado no artigo 6o da Constituição Federal de 1988, pela Emenda Constitucional no 64 de 2010.
5 A ANA é composta pelos seguintes movimentos sociais: Confederação Nacional dos Trabalhadores na Agricultura (CONTAG), Via Campesina, Movimento dos Pequenos Agricultores (MPA), Movimento de Mulheres Camponesas (MMC), Federação dos Trabalhadores e Trabalhadoras na Agricultura Familiar (FETRAF), União das Cooperativas da Agricultura Familiar e Economia Solidária
(UNICAFES), Associação Brasileira de Agroecologia (ABA) e redes regionais como a Articulação do Semi Árido (ASA), Rede Ecovida, Rede Cerrado e ANA Amazônia. Além dos movimentos sociais, compõem também a ANA, Ong’s de assessoria. 
A Lei Orgânica de Segurança Alimentar e Nutricional - LOSAN (Lei no 11.346/2006), já afirmava no art. 2 que:

\begin{abstract}
A alimentação adequada é direito fundamental do ser humano, inerente à dignidade da pessoa humana e indispensável à realização dos direitos consagrados na Constituição Federal, devendo o poder público adotar as políticas e ações que se façam necessárias para promover e garantir a segurança alimentar e nutricional da população.
\end{abstract}

O reconhecimento do DHAA, um processo longo e complexo, inicia-se com a definição conceitual de segurança alimentar e nutricional pelo Fórum Brasileiro de Segurança Alimentar e Nutricional, em 2003, em seguida, aprovada pela II Conferência Nacional de Segurança Alimentar e Nutricional, em 2004. Atenta-se ao fato de que essa Conferência foi resultado de uma construção entre Governo e sociedade civil.

A SAN, de acordo com o art. 3o da LOSAN, consiste:

[...] Na realização do direito de todos ao acesso regular e permanente a alimentos de qualidade, em quantidade suficiente, sem comprometer o acesso a outras necessidades essenciais, tendo como base práticas alimentares promotoras de saúde que respeitem a diversidade cultural quer sejam ambiental, cultural, econômica e socialmente sustentáveis.

Esse conceito está em consonância com os princípios adotados pelas resoluções internacionais, desde que o direito à alimentação passou a ser incorporado aos demais direitos humanos, estabelecidos na Carta dos Direitos Humanos de 1948.

Desta forma, destaca Maluf [22] que a SAN torna-se um objetivo público com "características que a coloca entre as categorias nucleares para a formulação das opções de desenvolvimento de um país".

$\mathrm{Na}$ visão de Delgado [8], a segurança alimentar e nutricional é fundamental porque combina e elabora alguns componentes essenciais para um outro modelo de desenvolvimento, relativizando as vantagens de uma agricultura voltada para a exportação baseada no agronegócio.
Portanto, o modelo produtivo agrícola passa a ser seguido para que se garanta a segurança alimentar e nutricional. De outro modo, a construção de uma agenda pública de SAN no Brasil leva a ser repensado o próprio modelo de desenvolvimento, desta vez levando-se em conta não uma agricultura voltada ao mercado externo, mas sim, ao abastecimento interno de alimentos. Tal debate aproxima a agenda de SAN da relacionada à agroecologia. Como visto em tópico anterior, a agenda política da agroecologia surge da crítica do modelo de desenvolvimento focado no agronegócio, propondo o fortalecimento da agricultura familiar a partir do reconhecimento das experiências agroecológicas existentes.

Destarte, confirma-se a prioridade da produção interna de alimentos de qualidade num volume compatível ao acesso e ao direito à alimentação. Além disso, incorpora-se a diversidade cultural existente no país, o fortalecimento da agricultura familiar e camponesa e a melhoria da renda das populações urbanas e rurais.

A Política Nacional de Segurança Alimentar e Nutricional (PNSAN) com vistas a assegurar o DHAA, institui como uma das diretrizes a "promoção do abastecimento e estruturação de sistemas descentralizados, de base agroecológica e sustentáveis de produção, extração, processamento e distribuição de alimentos" corroborando para o que afirma Olivier de Schutter [23] (p. 9):

[...] um conceito coerente para projetar os sistemas agrícolas futuros, fortemente enraizado tanto na ciência quanto na prática e porque apresenta fortes conexões com os princípios do direito à alimentação adequada [...].

e ainda,

[...] como um meio de desenvolvimento agrícola que não apenas apresenta fortes conexões conceituais com o direito à alimentação, mas tem resultados comprovados para um rápido progresso na concretização deste direito [...] [23] (p. $17)$. 
Observa-se, portanto, a recomendação de equacionar crescimento econômico com equidade social para que as pessoas tenham acesso aos bens básicos, sobretudo a alimentação adequada.

Assim, os debates em torno da garantia da segurança alimentar e nutricional são somados aqueles da promoção da agroecologia. Desta forma, eventos são promovidos com o intuito de aproximar a discussão das agendas propondo a agroecologia como um enfoque para um desenvolvimento rural com garantia do direito à alimentação. Em termos de ações globais, o Relator de Direitos Humanos da Organização das Nações Unidas (ONU) produziu um relatório especial afirmando que a agroecologia contribui para tornar efetivo o direito à alimentação adequada. Esse direito deve ser entendido quanto à disponibilidade (a agroecologia aumenta a produtividade no campo), à acessibilidade (a agroecologia reduz a pobreza rural), à adequação (a agroecologia contribui para melhorar a nutrição), à sustentabilidade (a agroecologia contribui para a adaptação às mudanças climáticas) e à participação dos agricultores para disseminação de boas práticas [23]. A FAO organizou o Seminário "Agroecologia para a segurança alimentar e nutricional" nos dias 18 e 19 de setembro de 2014, em Roma e em seguida, debates regionais. $\mathrm{O}$ "Seminário regional da FAO sobre agroecologia na América Latina e Caribe" foi realizado em Brasilia, em junho de 2015.

Autores, como Caporal e Petersen [24] e Schmitt e Grisa [25], destacam que a partir do primeiro governo Lula, em 2003, os sujeitos sociais tiveram mais espaço para discutir e apresentar as ideias sobre modelos de desenvolvimento "alternativos para o campo": espaços consultivos e deliberativos nos conselhos, como, por exemplo, no Conselho Nacional de Segurança Alimentar e Nutricional (CONSEA) e no Conselho Nacional de Desenvolvimento Rural Sustentável (CONDRAF), e em comissões como a Comissão Nacional de Desenvolvimento Sustentável dos Povos e Comunidades Tradicionais (CNPCT), dentre outras instâncias de participação social. Além destes espaços, mantiveram-se negociações diretas com gestores públicos diante de pautas estruturadas e jornadas de lutas.

O CONSEA tendo a representação de dois terços da sociedade civil, dentre eles alguns representantes do movimento agroecológico, exerceu importante papel na articulação de diversos movimentos e sujeitos sociais para inserir a agroecologia na agenda das políticas públicas.

Fica evidente que desafios no tratamento das pautas de SAN e agroecologia se fazem presentes uma vez que observamos a tendência das políticas públicas no amparo ao modelo de desenvolvimento baseado no agronegócio. Ao comparar o último Plano Safra da Agricultura Familiar, período 2016/2017, cujo tema é "alimentos saudáveis no campo e na cidade" ao Plano Agrícola e Pecuário do mesmo período, a linha de financiamento destinada ao médio e grande produtor para a produção de commodities, temos apenas $14 \%$ do montante orçamentário destinado ao público da agricultura familiar em relação aqueles dos médios e grandes produtores. Considerando-se que o segmento da agricultura familiar representa $84 \%$ do total de estabelecimentos com $74 \%$ do pessoal ocupado no meio rural, segundo dados do Censo Agropecuário de 2006, percebemos a assimetria de investimentos que evidenciam a opção pelo modelo de desenvolvimento a ser seguido pautado no agronegócio.

Movimentos sociais articulados em redes internacionais como é o caso da Via Campesina afirmam que o público da agricultura familiar e camponesa seria aquele que priorizaria um modelo de desenvolvimento com base na agroecologia e, por consequência garantiria o abastecimento alimentar, reafirmando a própria soberania alimentar. $\mathrm{Na}$ perspectiva cética abordada por Bersntein [26], os limitantes de tal estratégia são considerados no peso global da concentração de empresas de insumos e os sistemas agroalimentares sobre a agricultura.

Atividades 'a montante' referem-se a como se asseguram as condições de produção, antes que a lavoura propriamente dita possa começar. Isso inclui a provisão dos implementos de trabalho ou 'insumos' (ferramentas, fertilizantes, sementes), bem como os mercados para terra, trabalho e crédito - e, principalmente, é claro, a mobilização do trabalho. Atividades 'a jusante' referem-se ao que ocorre com as safras e animais quando deixam a propriedade rural sua comercialização, processamento e distribuição -e como essas atividades afetam a renda dos agricultores, necessária à reprodução dos mesmos. Agentes influentes a montante e a jusante da lavoura, na atual agricultura capitalista, estão representados, respectivamente, pelo capital de insumos agrícolas e pelo capital agroalimentar. 
O autor aborda processos de resistência como aqueles empreendidos pela Via Campesina porém, ressalta que agricultores são passíveis da diferenciação social imposta pelo desenvolvimento do capitalismo e pela crescente agricultura industrial corporativa que os ameaça.

Trata-se portanto de desafios a serem superados para que se defina e apoie determinado segmento da agricultura para que a agroecologia possibilite a maiores ganhos em termos de garantia da segurança alimentar e nutricional.

No tópico posterior apresentaremos políticas públicas que colaboram com a institucionalização da agroecologia no Estado brasileiro.

\section{A Agroecologia nas Políticas Públicas}

A partir das pautas empreendidas pelos movimentos sociais vão se formulando medidas pelas quais o Estado vai respondendo as necessidades colocadas para atingir as metas de um desenvolvimento rural sustentável e solidário. Instrumentos de políticas públicas são criados, ampliados e/ou readequados. Importantes alterações começaram a ocorrer nas relações entre Estado e sociedade civil a partir de 2003 quando são retomados espaços de diálogo. Atores até então marginais nas arenas públicas tiveram oportunidades de participar diretamente destes espaços e reivindicar suas pautas.

As Conferências Nacionais de Segurança Alimentar e Nutricional e as de Desenvolvimento Rural Sustentável passaram a pautar a agroecologia e, por consequências ações de políticas públicas nacionais incorporaram, ao menos em parte, as proposições elaboradas por organizações promotoras da agroecologia.

$\mathrm{Na}$ conformação das políticas públicas, considerando-se a esfera federal, uma lista de programas, projetos ou ações têm contribuído para a promoção da agroecologia e da produção orgânica, dentre as quais pode-se destacar: i) o Programa Nacional de Agrobiodiversidade, inserido no Plano Plurianual (PPA) 2008-2011, que buscou a promoção de sistemas sustentáveis de agricultura, fomentando práticas agroecológicas de agricultores e agricultoras familiares, povos e comunidades tradicionais, por meio da conservação da biodiversidade e de seu componente cultivado, além de promover a soberania e a segurança alimentar dos povos; ii) o Programa de Ação Nacional de Combate à Desertificação e Mitigação dos Efeitos da Seca - PAN Brasil , cujo objetivo, dentre outros, é a criação de instrumentos para o apoio ao desenvolvimento de atividades produtivas que apoiem a preservação, a conservação e o manejo sustentável dos recursos naturais; iii) o Programa de Organização Produtiva de Mulheres Rurais que tem como uma de suas finalidades $\mathrm{o}$ apoio às organizações produtivas no que diz respeito às ações baseadas na agroecologia e na preservação da biodiversidade; iv) o Programa de Desenvolvimento da Agricultura Orgânica cujo principal marco legal é a Lei Federal no 10.831, de 23 de dezembro de 2003, regulamentada pelo Decreto Federal no 6.323, de 27 de dezembro de 2007. Essa Lei não apenas estabeleceu o sistema nacional de produção orgânica como também definiu os critérios para produção, armazenamento, rotulagem, transporte, certificação, comercialização e fiscalização dos produtos orgânicos; v) o ensino formal com enfoque agroecológico fomentado pelo Ministério da Educação; vi) a Política Nacional de Educação Ambiental, Lei no 9.795, de 27 de abril de 1999; vii) o Programa de Educação Ambiental e Agricultura Familiar (PEAAF) com um de seus quatro objetivos voltados para a promoção da agroecologia e das práticas produtivas sustentáveis; e, viii) o Programa Cisternas que fomenta a construção de cisternas de placas de cimento, ampliando as condições da inclusão produtiva das famílias rurais de baixa renda, residentes na região do Semiárido com a valorização de conhecimentos dos agricultores que desenvolvem tecnologias sociais de convivência com o semiárido.

Outras políticas públicas que tiveram o protagonismo do movimento agroecológico no Brasil para sua elaboração e controle social foram o Programa de Aquisição de Alimentos (PAA) e o Programa Nacional de Alimentação Escolar (PNAE), ambos com sobrepreço de $30 \%$ para os produtos agroecológicos ou orgânicos. Soma-se à lista, a Política de Garantia de Preços Mínimos para Produtos da Sociobiodiversidade (PGPM - Bio), garantindo um atendimento específico para os extrativistas.

Esses instrumentos permitiram, por um lado, garantir e ampliar a oferta de alimentos e, por outro, criar medidas efetivas e coordenadas de acesso a esses alimentos em quantidade e qualidade suficientes, inclusive para segmentos da população vulneráveis à insegurança alimentar. Neste sentido, segundo Schmitt 
e Grisa [25], tais programas permitiram a inserção econômica dos agricultores familiares, a promoção de dinâmicas locais de desenvolvimento, a criação de novos espaços de comercialização, a valorização de circuitos curtos de produção e consumo e a reprodução social das unidades familiares de produção. Essas ações contribuem para a construção da agroecologia com alguns aspectos em comum. Elas possibilitam: o fortalecimento das práticas extrativistas e da reprodução social de quem vive delas, promovendo a sustentabilidade; produtos do extrativismo e os adquiridos pelo PAA e PNAE apresentam enraizamento cultural nos territórios e contribuem para resgatar e valorizar alimentos locais, conhecimentos tradicionais, práticas culturais e alimentares, ambos os programas enfatizam o fornecimento de alimentos saudáveis às populações em situação de insegurança alimentar e nutricional, especialmente o PNAE.

Os três programas demonstram como o enfoque da agroecologia nas políticas públicas foi vinculado à segurança alimentar e nutricional e à agricultura familiar. Espaços como o CONSEA constituíram-se em arenas importantes para influenciar a formulação e implementação de novos instrumentos e programas.

Um exemplo de ampliação é o caso do Programa Nacional de Fortalecimento da Agricultura Familiar (PRONAF) que cria uma linha específica para a agroecologia - ainda que pouco expressiva se comparada ao montante dos recursos utilizados fora desta perspectiva. A Política Nacional de Assistência Técnica e Extensão Rural (PNATER) estabelece em seus princípios, o apoio às atividades de extensão rural em base ecológica, como enfoque preferencial para o desenvolvimento de sistemas de produção sustentáveis, assim como a adoção de metodologia participativa, com enfoque multidisciplinar, interdisciplinar e intercultural, buscando a construção da cidadania e a democratização da gestão da política pública. Cabe ainda destacar um dos objetivos previstos dessa Lei que consiste em "desenvolver ações voltadas ao uso, manejo, proteção, conservação e recuperação dos recursos naturais, dos agroecossistemas e da biodiversidade".

Para Caporal e Petersen [24] é na PNATER que a palavra agroecologia aparece pela primeira vez em uma política pública nacional como orientação para a ação dos extensionistas rurais brasileiros,
Em 2011, as experiências de agroecologia desenvolvidas por agricultores familiares, povos e comunidades tradicionais, vinham fazendo parte de um amplo processo de demandas por uma legislação específica para a agroecologia. Mas, a pauta da 4a Marcha das Margaridas que ocorreu em 2011, finalmente trouxe o tema da agroecologia para o centro do debate político.

A demanda proposta na pauta da Marcha foi encaminhada ao Ministério do Meio Ambiente que se incumbiu de criar um Grupo de Trabalho Interministerial e inicia a elaboração do Plano em diálogo com a sociedade civil que proporcionou espaços para a construção e a implementação de tal Política.

Em sua formulação, a PNAPO possibilitou considerar importantes dinâmicas em curso, articulando e fortalecendo programas já existentes no Governo Federal referentes à produção, aos mercados, a geração do conhecimento, à educação e às políticas específicas para a juventude e as mulheres no campo agroecológico. Como exemplo, destaca-se o que vem ocorrendo na comercialização dos produtos da sociobiodiversidade oriundos de sistemas produtivos, reconhecidamente agroecológicos e de uso sustentável das florestas, historicamente manejados por povos e comunidades tradicionais e por agricultores familiares em todos os biomas brasileiros, cuja atividade é determinante para a sua reprodução socioambiental e cultural.

Observou-se, com a regulamentação da PNAPO, avanços na criação de espaços de diálogo entre Estado e sociedade mediante a instalação da Comissão Nacional de Agroecologia de Produção Orgânica (CNAPO), cuja secretaria-executiva coube à Secretaria Geral da Presidência da República. A elaboração, a execução, o acompanhamento e a avaliação do I Plano Nacional de Agroecologia e Produção Orgânica (PLANAPO), principal instrumento de execução estabelecido pela PNAPO teve a participação de representantes do governo e da sociedade civil.

O fato da gestão da política, no que concerne a participação da sociedade civil e dos diferentes órgãos de governo ter ficado a cargo da Secretaria Geral da Presidência da República e não de um ministério em específico, possibilitou maior intersetorialidade dos 
objetivos e metas. As ações passaram a ser menos segmentadas no nível do Estado, proporcionando, inclusive, uma inovação em termos de gestão na articulação interconselhos. Foram promovidos espaços de discussão de pautas comuns como é o caso de reunir num mesmo momento a CNAPO, o CONSEA e o CONDRAF.

Ainda que seja possível considerar avanços na formulação de políticas públicas de apoio a agroecologia, propulsores de estilos de agriculturas em sistemas de produção sociobiodiversos, promotores da agricultura familiar e camponesa e da segurança alimentar e nutricional, por outro lado, é factível observar que nos governos que compreendem o período de análise deste artigo, sendo eles Governo Lula (2003-2010) e o Governo Dilma (2010-2014), tais avanços aconteceram e acontecem num contexto de expansão do agronegócio e das formas privadas de apropriação dos recursos naturais a ela associadas [27]. Neste sentido, um dos maiores limites da PNAPO consiste na efetivação de políticas relativas à distribuição e ao acesso à terra e à água que possibilitem a transição para modos de produção, de fato, agroecológicos, garantindo às populações, os seus territórios, fato contundentemente levantado pelos movimentos sociais, compondo uma das principais críticas da sociedade civil à PNAPO.

\section{CONSIDERAÇÕES FINAIS}

Este artigo buscou ressaltar, por meio de análise documental do marco legal do período dos anos 2003 a 2012, que a agroecologia possui potencialidades para promover a segurança alimentar e nutricional, por meio de agriculturas mais sustentáveis e mais inclusivas socialmente. Para tanto, enfatiza o fortalecimento das populações do campo, das florestas e das águas, aqui denominadas, como a agricultura familiar e camponesa, as quais possuem hoje representações no movimento agroecológico brasileiro. Desta forma, observou-se uma afirmação do Estado para permitir conexões multisetoriais que possibilitam de um lado a ampliação da oferta de alimentos saudáveis produzidas mediante uma abordagem agroecológica e, de outro, o atendimento de uma demanda do Sistema Nacional de Segurança Alimentar e Nutricional no Brasil. Tais temas confluem para uma formulação estratégica na agenda do Estado, conformando políticas públicas com o propósito de estabelecer um modelo de desenvolvimento rural mais democrático, menos centrado em commodities e mais voltado à garantia do Direito Humano à Alimentação Adequada e Saudável.

Ainda que sejam apresentados avanços destacados em termos do número de iniciativas, expressas sobretudo no I Plano Nacional de Agroecologia e Produção Orgânica, em se tratando da institucionalização da agroecologia nas políticas do Estado, existem diversas dificuldades ao seu acesso e até mesmo na sua execução para atender objetivos traçados.

A PNAPO completou quatro anos em agosto de 2016 e, como uma política ainda jovem, tem lacunas a serem vencidas. Dentre elas, podemos citar: a falta de fortalecimento da gestão e o monitoramento participativo e sistemático da política e seu principal instrumento de execução - o PLANAPO; a falta de estratégia do tratamento do tema da agricultura urbana e periurbana; o marco legal (sanitário, fiscal, tributário e ambiental); a necessária redução do uso de agrotóxicos e, para tanto, o lançamento e a implementação do Programa Nacional de Redução do Uso de Agrotóxicos (PRONARA); a democratização do acesso à água e; democratização do acesso a terra e defesa dos territórios de identidade.

Por fim, afirmamos que as lutas e as disputas no campo da agroecologia e SAN foram favorecidas por um contexto político de maior participação e protagonismo social. Consequentemente possibilitaram a emergência da agroecologia na agenda do desenvolvimento rural brasileiro ainda que com frágil expressão se comparada ao modelo de desenvolvimento hegemônico alicerçado em ganhos econômicos do agronegócio.

\section{REFERÊNCIAS}

[1] Wanderley MNB. Agricultura familiar e campesinato: rupturas e continuidade. Estud. Soc. Agric. 2004;21:42-61.

[2] Food and Agriculture Organization of the United Nations FAO. Anais da 31. Conferencia Regional para América Latina y el Caribe [internet]; 26-30 de abril de 2010. Ciudad de Panamá (Panamá); 2010. Disponível em: http://www.fao.org.br

[3] Assis RL. Globalização, Desenvolvimento Sustentável e Ação Local: O Caso da Agricultura Orgânica. Cadernos de Ciência \& Tecnologia. 2003;20(1):79-96. 
[4] Delgado NG. O papel do rural no desenvolvimento nacional: da modernização conservadora dos anos 1970 ao Governo Lula. In: Ministério do Desenvolvimento Agrário (BR). Brasil rural em debate. Brasília: CONDRAF/MDA; 2010. p. 28-78.

[5] Muller G. Complexo agroindustrial e modernização agrária. São Paulo: Hucitec; 1989.

[6] Silva JG. A industrialização e a urbanização da agricultura brasileira. São Paulo em Perspectiva. 1993;7(3):2-10.

[7] Mendonça S. A nova hegemonia do patronato agrário brasileiro: da organização das cooperativas brasileiras à Associação Brasileira de Agribusiness. Antítese - marxismo e cultura socialista, Goiânia; 2006.

[8] Delgado G. Reestruturação da economia do agronegócio anos 2000. In: Stedile JP, Estevam D. A questão agrária: o debate na década de 2000. São Paulo: Ed. Expressão Popular; 2013. p. $57-87$.

[9] Alentejano PRR, Silva TLA. Ocupações, acampamentos e assentamentos: o descompasso entre a luta pela terra e a política agrária do governo Lula. Conflitos no Campo Brasil. Rio de Janeiro; 2008.

[10] Schneider S. Teoria social, agricultura familiar e pluriatividade. Rev. Bras. Ci. Soc. 2003;18(51):99-122.

[11] Gramsci A. Cadernos do Cárcere. Vol. 1. Introdução ao estudo da filosofia - A filosofia de Benedetto Croce. Rio de Janeiro: Civilização Brasileira; 2001.

[12] Mendonça S. O Estado ampliado como ferramenta metodológica. Marx e o Marxismo [internet]. 2014 [acesso em 15 jun 2015];2(2):27-43. Disponível em: http://www.marxeomarxismo.uff.br/index.php/MM/article/d ownload $/ 35 / 32$

[13] Molina MG. Introducción a la agroecología. Cuadernos Técnicos. Série Agroecología y ecología agrária. Valencia: Sociedad Española de Agricultura Ecológica (SEAE); 2011.

[14] Altieri M. Agroecología - Bases científicas para una agricultura sustentable. Montevideo: Ed. Nordan-Comunidad; 1999.

[15] Sevilla-Guzmán E. La agroecologia como estrategia metodológica de transformación social. Agroecología Y Gestión De Ambientes Rurales [internet]. 2009 [acesso em 15 jun 2014]. Disponível em: http://agroeco.org/brasil
[16] Amman SB. Ideologia do desenvolvimento de comunidade no Brasil. 6ed. São Paulo: Cortez Editora; 1987.

[17] Petersen P, Dias A. Construção do conhecimento agroecológico: novos papéis, Novas Identidades. Caderno do II Encontro Nacional de Agroecologia. Rio de Janeiro: Gráfica Popular; 2007.

[18] Gliessman SR. Agroecologia: processos ecológicos em agricultura sustentável. Porto Alegre: Ed. da Universidade; 2000.

[19] Canuto JC. Agricultura Ecológica en Brasil: Perspectivas socioecológicas [tese]. Córdoba-España: ISEC/Universidad de Córdoba; 1998.

[20] Ploeg JD. Camponeses e impérios alimentares: lutas por autonomia e sustentabilidade na era da globalização. Porto Alegre: UFRGS; 2008.

[21] Brasil. Câmara Interministerial de Agroecologia e Produção orgânica (CIAPO). Plano Nacional de Agroecologia e Produção Orgânica. Brasília: MDA; 2013.

[22] Maluf RS. Segurança alimentar e Nutricional. 3ed. Petrópolis: Vozes; 2011.

[23] Schutter O. Agroecologia e o Direito Humano à Alimentação Adequada. Brasília (DF): MDS; 2012.

[24] Caporal F, Petersen P. Agroecologia e políticas públicas na América Latina: o caso do Brasil. Agroecología. 2012;6:63-74.

[25] Schmitt CJ, Grisa C. Agroecologia, mercados e políticas públicas: uma análise a partir dos instrumentos de ação governamental. In: Niederle PA, Almeida L, Machado F. Agroecologia: práticas, mercados e políticas para uma nova agricultura. Curitiba: Kairós Edições; 2013. p.215-265.

[26] Berstein H. Soberania alimentar: uma perspectiva cética. Sociologias. 2015;17(39):276-336.

[27] Brasil. Conselho de Segurança Alimentar e Nutricional (CONSEA). A segurança alimentar e nutricional e o direito humano à alimentação adequada no Brasil - indicadores e monitoramento - da Constituição de 1988 aos dias atuais. Brasília (DF): CONSEA; 2010. 